\title{
Orientation-contingent tactual size aftereffects
}

\author{
JAMES T. WALKER \\ University of Missouri-St. Louis, St. Louis, Missouri 63121
}

\begin{abstract}
A new contingent aftereffect of apparent size can be produced in the following way. A rectangular inspection block is oriented with its long dimension horizontal (or vertical). During an inspection (induction) period of $2 \mathrm{~min}$, the subject alternately grasps the horizontal and vertical dimensions of the inspection block between the thumb and forefinger of a single hand, changing from one dimension to the other every 2 sec. After the inspection period, the horizontal dimension of a square test block feels shorter (or longer) than the vertical dimension. Inspection blocks having larger ratios of width to height produce larger aftereffects. The aftereffect persists over delays of as much as $16 \mathrm{~min}$ between inspection and test.
\end{abstract}

This paper describes a new contingent aftereffect of apparent size in the tactual-kinesthetic (haptic) modality. Using the thumb and forefinger of a single hand, the subject alternately grasps the long and short dimensions of a rectangular inspection block (see Figure 1) during an inspection period of $2 \mathrm{~min}$, changing from one dimension to the other every $2 \mathrm{sec}$. After the inspection period, the subject then alternately grasps the horizontal and vertical dimensions of the square test block. If the long dimension of the rectangular inspection block is oriented horizontally, then the horizontal dimension of the test square subsequently feels shorter than the vertical dimension; and if the long dimension of the inspection block is vertical, then the vertical dimension of the test square feels shorter. Thus, the present aftereffect-like most others-is a negative aftereffect. The aftereffect is readily produced using blocks of cardboard or plastic lying on a horizontal surface, or attached to a vertical surface.

The present phenomenon is a species of contingent aftereffect, since the tactually perceived size of a test square is contingent-dependent-on the horizontal or vertical orientation of the subject's fingers. The horizontal and vertical dimensions of the test square constitute identical finger-span stimuli, yet one of these dimensions feels larger to the fingers of the same hand, depending on whether the long dimension of the inspection rectangle was horizontal or vertical.

A great many contingent aftereffects have been demonstrated in the visual modality-for example, a gaze-contingent color aftereffect (Kohler, 1964);

Some of the results of this study were presented to the annual meeting of the Psychonomic Society, Denver, Colorado, November 1975. I am very grateful to Virginia Gossage for running all of the subjects in this study. Requests for reprints should be sent to James T. Walker, Department of Psychology, University of Missouri-St. Louis, St. Louis, Missouri 63121.

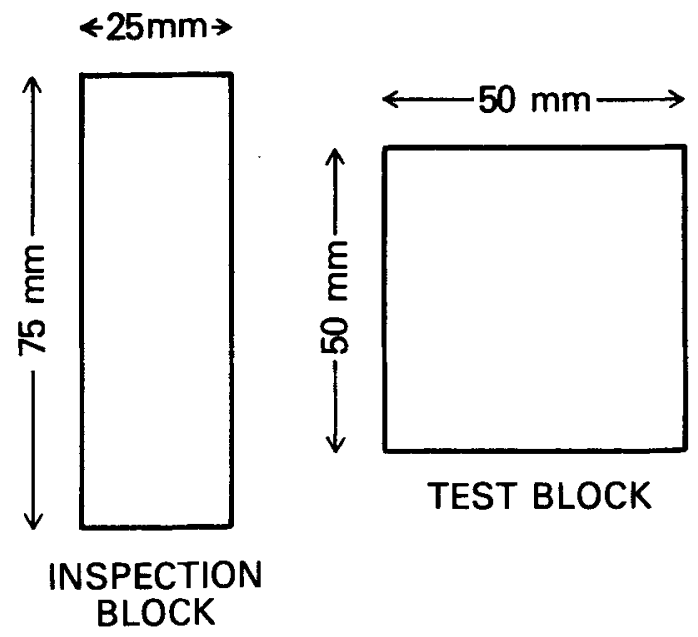

Figure 1. Inspection and test blocks used in Experiments 1 and 3 .

the McCollough effect, an orientation-contingent color aftereffect (McCollough, 1965); a colorcontingent orientation aftereffect (Held \& Shattuck, 1971); motion-contingent color aftereffects (Hepler, 1968; Stromeyer \& Mansfield, 1970); color-contingent motion aftereffects (Favreau, Emerson, \& Corballis, 1972); and texture-contingent visual motion aftereffects (Mayhew \& Anstis, 1972; Walker, 1972). In each case, during an inspection period, there is a pairing of two sensory dimensions-such as color and orientation or size and position. During a subsequent test period, the perception of an object on one sensory dimension is contingent on its location on the other sensory dimension.

For every pair of sensory dimensions where contingent aftereffects have been demonstrated, aftereffects have also been produced within each of the dimensions taken separately-such familiar phenomena as afterimages, motion aftereffects, and visual and kinesthetic figural aftereffects. Those con- 
ventional aftereffects involving only one sensory dimension will be called simple aftereffects, following Mayhew and Anstis (1972).

The great majority of contingent aftereffects demonstrated so far have involved the visual modality. However, the earliest demonstration of a contingent aftereffect-although it was not described as such at the time-may be that of Gibson (1933), involving the haptic (tactual-kinesthetic) modality. Rubbing a curved edge with the fingers of one hand produces an aftereffect of apparent curvature in the opposite direction in a subsequently presented straight edge. As the fingers move left and right along a curved edge, they are displaced from a straight line, and that displacement is contingent on the left-right location of the hand. To the extent that the perception of curvature depends on the perception of the displacement of the moving hand and fingers, Gibson's aftereffect would appear to be a contingent one. But holding the fingers motionless on a curved edge also produces an aftereffect of curvature, as Walker and Shea (1974) have noted. Thus, it is not clear that Gibson's curvature aftereffect is wholly a contingent aftereffect.

Köhler and Dinnerstein (1947) demonstrated an aftereffect in the kinesthetic modality that is more clearly a contingent aftereffect, although those workers-like Gibson (1933)-did not describe their phenomenon as a contingent aftereffect. Rubbing a tapered inspection bar between the thumb and forefinger of one hand produces an aftereffect of apparent taper in the opposite direction in a rectangular test bar. When the subject rubs the parallel edges of the test bar, the same sensory receptors perceive the same finger span as larger or smaller, depending on whether the hand is moving toward the former location of the narrow or the wider end of the tapered inspection bar. Thus, the aftereffect is contingent on the direction of movement of the hand. Unfortunately, no quantitative measurements of that contingent aftereffect were reported.

Walker and Shea (1974) produced and measured a contingent aftereffect of tactual size occurring in a single hand. After alternately grasping a narrow inspection block located on the subject's left and a wide block located on the right, a test block of intermediate width presented on the left feels wider than a test block of the same intermediate width presented on the right. Thus, a location-contingent tactual size aftereffect occurs. Since the aftereffect in the present study can be described as an orientationcontingent tactual size aftereffect, the present study can be viewed as an extension of the earlier work of Walker and Shea.

Besides demonstrating the contingent taper aftereffect described above, Köhler and Dinnerstein (1947) also demonstrated simple kinesthetic figural aftereffects that appear analogous in many respects to simple visual figural aftereffects (Köhler \& Wallach, 1944). Grasping a narrow inspection block with one hand and a wide block simultaneously with the other hand produces an aftereffect in the apparent size of equal and intermediate test blocks subsequently presented to the two hands. This procedure produces simple negative aftereffects in opposite directions in the two hands-that is, an aftereffect of overestimation occurs in one hand and an aftereffect of underestimation occurs in the other. Presenting a single inspection block, wide or narrow, to a single hand also produces a simple negative aftereffect that can be readily measured-and indeed, Charles and Duncan (1959) have argued that such a method constitutes a superior procedure for making quantitative measurements. In the contingent aftereffect that is the subject of the present study, in the earlier taper aftereffect of Köhler and Dinnerstein, and in the contingent size aftereffect of Walker and Shea, two negative aftereffects occur in a single handand those aftereffects are in opposite directions.

In the present study of orientation-contingent aftereffects of tactual size, three experiments were designed for the following purposes: (1) to measure the aftereffect using a magnitude estimation procedure; (2) to measure the effects of inspection blocks having different ratios of height to width; and (3) to measure that time course of the aftereffect. The measurement procedures in the present study are very similar to the magnitude estimation procedures used earlier by Walker and Shea (1974).

\section{EXPERIMENT 1}

This experiment was designed to assess the feasibility of using a method of magnitude estimation to measure the aftereffect.

\footnotetext{
Method

Subjects. Six women and six men, introductory psychology students at the University of Missouri-St. Louis, participated as a course requirement. Two men were replaced as subjects for the reason set out below. Only one subject was left-handed.

Apparatus. The inspection block was a rectangle, $75 \times 25 \mathrm{~mm}$, and the test block was a 50-mm square. Each block was cut from sheet Plexiglas about $6 \mathrm{~mm}$ thick, and each was cemented to a separate $15-\mathrm{cm}$-square sheet of Plexiglas. For control purposes, five preinspection measures were made using blocks having the following combinations of horizontal and vertical dimensions in millimeters: H50 V60, H50 V 55 , H50 V50, H55 V50, and H60 V50. The stimuli were mounted in a vertical plane and were presented facing the subject. A white cardboard screen hid the stimuli from the subject's view. The apparatus was arranged so that the long dimension of any of the blocks could be presented horizontally or vertically as required. Thus, the five preinspection measures described above were made using only three different blocks, one of which was also used as the test block.

Procedure. Using the $50 \times 60 \mathrm{~mm}$ preinspection block, each subject made a practice judgment with the long dimension hori-
} 
zontal and a second practice judgment with the long dimension vertical. The experimenter placed the subject's right thumb and forefinger across the horizontal dimension of the block and then across the vertical dimension, explaining that the horizontal dimension was the width and the vertical dimension the height of the block. The subject then alternately grasped the width and the height of the block for $2 \mathrm{sec}$ each, changing from one dimension to the other in time with a metronome ticking at the rate of $1 \mathrm{beat} / \mathrm{sec}$. The vertical dimension was always grasped with the thumb downward. The experimenter asked whether the width or the height felt larger, and then asked, "If the smaller dimension is $50 \mathrm{~mm}$, how large is the larger?' Subjects were given as much time as they needed, but they were encouraged to make their judgments as quickly and accurately as possible. Test judgments required about 15 to $45 \mathrm{sec}$.

After the practice judgments, five control measures were made using the preinspection stimuli described above. The order of preinspection stimuli was randomized independently for each subject. During the practice and preinspection judgments, if a subject indicated that one dimension of any block felt as much as $50 \mathrm{~mm}(100 \%)$ larger than the other dimension, then the experimenter asked, "It feels twice as large as the other one, right?" Any subject who maintained such an extreme judgment was replaced. Since the largest objective difference between the width and height of any of the preinspection blocks was only $10 \mathrm{~mm}$ $(\mathbf{2 0 \%})$, those subjects who made extreme judgments, as defined above, were eliminated in the interest of reducing error variance. Two potential subjects were excluded from the experiment for that reason.

An inspection period of 2 min followed the preinspection measurements. The long dimension of the inspection block was horizontal for half the subjects and vertical for the other half, and those orientations of the inspection block were balanced across the sexes. During the inspection period, the subject alternately grasped the horizontal and vertical dimensions of the inspection block in time with the metronome, as in the practice and preinspection procedures. After the inspection period, the experimenter quickly replaced the inspection block with the test block, which the subject then judged in the way described above.

\section{Results}

Preinspection measures. For each preinspection block, the objective percentage difference is defined as the percentage by which the longer dimension exceeds the shorter. An objective percentage difference was given a negative sign where the vertical dimension was longer and a positive sign where the horizontal was longer. Thus, the objective percentage differences for the preinspection blocks listed above are, respectively, $-20 \%,-10 \%, 0 \%, 10 \%$, and $20 \%$. The subjective percentage difference is the percentage by which the subject judged the apparently longer dimension of a preinspection block to exceed the apparently shorter dimension, the apparently shorter dimension always being assigned a value of $50 \mathrm{~mm}$, as indicated earlier. Subjective percentage differences were treated like objective ones with regard to sign, that is, negative values indicate that the vertical dimension was judged longer.

The results of the preinspection measures are shown in Figure 2, where the horizontal axis represents the objective percentage differences and the vertical axis the subjective ones. A repeatedmeasures analysis of variance showed the effect of the objective percentage differences to be highly significant $[F(4,44)=31.47, p<.001]$. A highly significant linear trend $[F(1,44)=123.58, p<.001]$ accounts for $72.75 \%$ of the within-subjects variance. Among the trend components of higher degree, only the cubic yielded an $F$ ratio greater than $1.00[\mathrm{~F}(1,44)$ $=1.80, \mathrm{p}<.25]$. The strong linear trend indicates that the subjects are capable of discriminating the differences between the horizontal and vertical dimensions of the preinspection blocks, and that finding thus serves to validate the measurement method.

Aftereffect measures. These measures were found by subtracting the mean of each subject's control measures-the subjective percentage differences for the preinspection measures-from the subjective percentage difference for the test measure. ${ }^{1}$ While the present aftereffect is a negative one, as noted earlier, all aftereffect measures in the expected direction were given a positive sign. The mean aftereffect, $14.37 \%$, was significantly different from zero [t(11) $=3.82, \mathrm{p}<.01]$. The aftereffect measures were subjected to a two-way analysis of variance where the factors were sex and orientation of the inspection block (long dimension horizontal or vertical). There was no significant effect of $\operatorname{sex}[F(1,8)=2.33$, $\mathrm{p}<.25]$ or orientation $[\mathrm{F}(1,8)=1.83, \mathrm{p}<.25]$, or any significant interaction $(\mathrm{F}<1)$.

\section{Discussion}

The present contingent aftereffect in the tactualkinesthetic modality does not differ significantly from the contingent aftereffect described earlier by Walker and Shea (1974), the means of those aftereffects being $14.37 \%$ and $8.41 \%$ respectively $[\mathrm{t}(26)$ $=1.33, \mathrm{p}<.20]$. Köhler and Dinnerstein (1947) found a simple kinesthetic figural aftereffect of

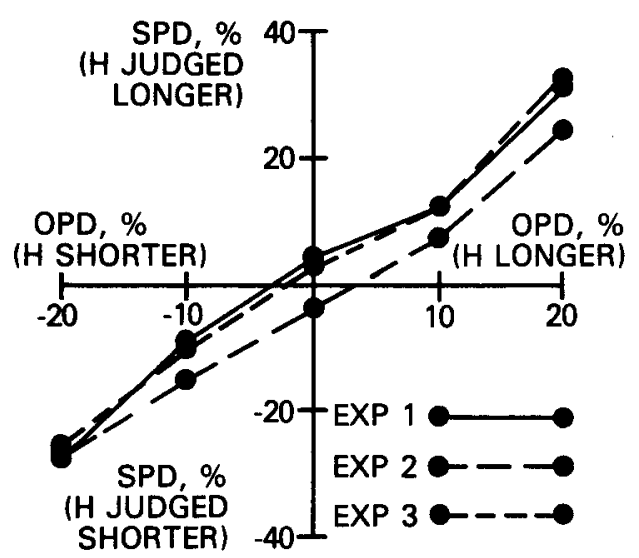

Figure 2. Preinspection measures. Subjects' judgments, subjective percentage differences (SPD), in relation to objective percentage differences (OPD) between horizontal and vertical dimensions of preinspection blocks. 
about $43 \%$ in an experiment using 50 subjects, but Wertheimer (1954) has argued convincingly that those results were inflated by constant errors that could be removed by proper control procedures. Using Köhler and Dinnerstein's inspection and test stimuli with procedures designed to eliminate constant errors, Wertheimer (1954) found a simple aftereffect of about $13 \%$ in an experiment using 60 subjects. Thus, the present contingent aftereffect appears rather comparable in magnitude to earlier measurements of simple kinesthetic figural aftereffects - although such comparisons must be made with caution, since those earlier measurements utilized a method of average error and the present ones a method of magnitude estimation.

\section{EXPERIMENT 2}

The purpose of this experiment was to measure the contingent aftereffect as a function of the difference between the width and height of a series of different inspection blocks.

\section{Method}

Subjects. Twelve men and 12 women, introductory psychology students, participated as a course requirement. One worman was replaced as a subject for the reason explained below. Only one subject was left-handed.

Apparatus. The same five preinspection blocks were used as in Experiment 1. There were four different inspection blocks having the following dimensions in millimeters: $\mathrm{H} 50$ V50, $\mathrm{H} 60 \mathrm{~V} 40$, $\mathrm{H} 70 \mathrm{~V} 30$, and $\mathrm{H} 90 \mathrm{~V} 10$. Thus, the differences between the horizontal and vertical dimensions of the inspection blocks were, respectively, $0,20,40$, and $80 \mathrm{~mm}$. In all other respects, the apparatus was the same as used in Experiment 1. The long dimensions of the inspection blocks were always oriented horizontally, since that orientation produced a numerically larger, though not significantly greater, aftereffect in Experiment 1.

Procedure. Two practice judgments and five preinspection measures were made, as in Experiment 1, except that in the present experiment the subject was given a limited amount of exposure to the stimuli. Using the dominant hand, the subject was allowed to grasp the horizontal dimension for $2 \mathrm{sec}$, the vertical for $2 \mathrm{sec}$, and then the horizontal and vertical once again for 2 sec each, all in time with a metronome ticking at 1 beat/sec. Thus, the subject was exposed to each stimulus block for $8 \mathrm{sec}$. The block was taken away, and the subject then judged the horizontal and vertical dimensions as in Experiment 1 . The same procedure was used for test measures. Since the aftereffect was expected to be smaller under some conditions in the present experiment, it was considered desirable to have the subjects respond as quickly as possible in order to avoid excessive dissipation of the aftereffect. One subject was replaced because of an extreme judgment, in accordance with the criterion established in Experiment 1.

Groups of six subjects were randomly assigned to one of the four inspection blocks. The sexes were balanced across inspection conditions. After the preinspection measures, the subject was given three inspection periods of 1 min each. A test measure was made immediately after each inspection period. Because of the small number of subjects in each experimental group, multiple test measures were made in the interest of reducing error variance. In order to reduce any subject's tendency to develop a response bias-that is, to give the same response on successive tests-a different test block was used for each test measure. The following test blocks were presented to each subject in an individually determined random order: H50-V60, H50-V50, and H60-V50. There were no intertrial intervals, as such, between successive inspection periods; those periods were separated by the time required for the presentation of the test blocks and for the subjects to make their judgments.

\section{Results}

Preinspection measures. These measures, shown in Figure 2, were found as in Experiment 1. A repeatedmeasures analysis of variance showed a highly significant effect of the objective percentage differences between the horizontal and vertical dimensions of the preinspection blocks $[\mathrm{F}(4,92)=37.93$, $\mathrm{p}<$ $.001]$. There was a highly significant linear trend accounting for $61.74 \%$ of the within-subjects variance, $[F(1,92)=150.48, p<.001]$, but no higher-degree trend component approached significance (all Fs $<1$ ). Thus, these results essentially replicate those of Experiment 1, insofar as the preinspection measures are concerned.

Aftereffect measures. For each subject, the mean subjective percentage difference for the preinspection measures was subtracted algebraically from the mean subjective percentage difference for the three test judgments. All aftereffect measures in the expected direction were given a positive sign. The mean aftereffects produced by the four inspection blocks are shown in Figure 3. Each mean differs significantly from zero [each $t(5)>2.75, p<.05$ ]. Since the means and variances of the aftereffect measures were correlated, a $\log (X+10)$ transformation was carried out before doing an analysis of variance. The differences between the widths and heights of the inspection blocks produced a significant effect $[F(3,20)=13.09, p<.01]$ and significant linear and quadratic trends [each $\mathrm{F}(1,20)>17, \mathrm{p}<.01$ ] but no significant cubic trend $[F(1,20)=1.62, \mathrm{p}<.25]$.

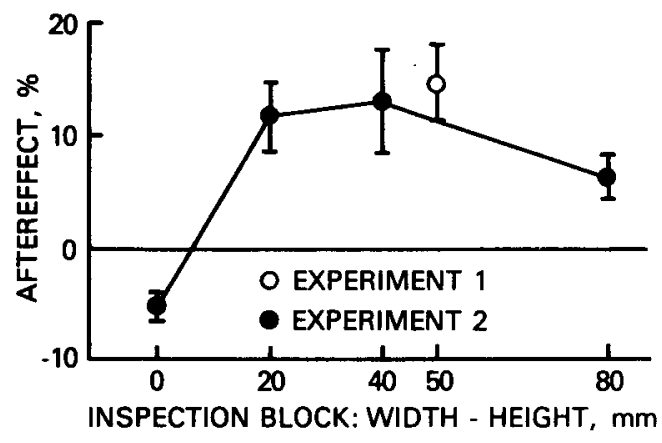

Figure 3. Aftereffect as a function of difference between horizontal and vertical dimensions of inspection blocks. Bars indicate \pm 1 standard error of the mean. 


\section{Discussion}

Following the analogies drawn by Köhler and Dinnerstein (1947) between kinesthetic and visual figural aftereffects (Köhler \& Wallach, 1944), the edges of the inspection and test blocks can be considered as representing inspection and test contours in the subject's tactual-kinesthetic space. In visual and kinesthetic figural aftereffects, as a rule, inspection contours repel test contours. The repulsion reaches a maximum at some particular separation between test and inspection contours, declining at higher and lower levels of separation. But even when the test and inspection contours coincide, the inspection contours typically exert some influence, usually involving a reduction in the perceived size of a test object (for example, Charles \& Duncan, 1959; Köhler \& Dinnerstein, 1947; Köhler \& Wallach, 1944).

In the present experiment, the separation between inspection and test contours is a function of the difference between the horizontal and vertical dimensions of the test blocks. The maximum aftereffect was produced by the $70 \times 30 \mathrm{~mm}$ inspection block, that is, the block having a difference of $40 \mathrm{~mm}$ between its horizontal and vertical dimensions. Thus, like other aftereffects, the present contingent aftereffect reached a maximum at an intermediate level of separation between inspection and test contours.

When the $50-\mathrm{mm}$ square was used as the inspection block, the horizontal dimension of the test blocks felt longer. That aftereffect was given a negative sign since it was in the opposite direction from the aftereffects which the other inspection stimuli were expected to produce. There was no separation between inspection and test contours when the same $50-\mathrm{mm}$ square was used as the inspection and test block. As noted above, aftereffects occur under such conditions, but there is no obvious reason why the horizontal-rather than the vertical-dimension of the test square should feel longer when the same square is used as the inspection block.

\section{EXPERIMENT 3}

This experiment was designed to measure the time course of the contingent aftereffect over delay intervals up to 16 min between the termination of the inspection period and the subsequent test.

\section{Method}

Subjects. Twenty women and 20 men, introductory psychology students, participated as a course requirement. One woman was replaced, as explained below. Five subjects were left-handed.

Apparatus. The inspection and test blocks were, respectively, the $75 \times 25 \mathrm{~mm}$ rectangle and the $50-\mathrm{mm}$ square which were used in Experiment 1. The same apparatus was used here as in the two previous experiments.

Procedures. Two practice judgments and five preinspection measures were made using the same procedures as in Experiment 2. One subject was replaced because of an extreme judgment, using the same criterion as in the two previous experiments.
The experiment was run in two phases. In the first phase, four men and four women were randomly assigned to each of the following delay intervals: 0,1 , or $2 \mathrm{~min}$. After the preinspection measures, the subject was given a 2 -min inspection period. The long dimension of the inspection block was horizontal for half the subjects and vertical for the other half. Those orientations were balanced across ihe sexes and across the delay intervals. After one of the delay intervals, above, a single test measurement was made. Since there was a substantial aftereffect after the 2 -min delay, additional subjects-eight men and eight women-were run in the second phase of the experiment with delay intervals of 8 and $16 \mathrm{~min}$. All of above variables were balanced. In the second phase of the experiment, all of the subjects left the experimental room to do as they pleased during the delay intervals; otherwise, the same procedure were used in both phases of the experiment.

\section{Results}

Preinspection measures. These measures, shown in Figure 2, were analyzed as in the preceding experiments. There was a highly significant linear trend accounting for $69.76 \%$ of the within-subjects variance $[F(1,156)=369.65, p<.001]$, and the cubic trend component approached significance $[F(1,156)$ $=3.24, \mathrm{p}<.10 \mathrm{~J}$. For the two remaining trend components, both $\mathrm{F}$ ratios were less than 1 . Thus, the present preinspection measures replicate the results of Experiments 1 and 2.

Aftereffect measures. Aftereffect measures were found using the same procedures as in Experiment 1. The results are shown in Figure 4. The mean aftereffect was significantly greater than zero at each of the delay intervals, values of $t(7)$ ranging from 2.05 to 4.05 , and one-tailed $\mathrm{p}$ values from .05 to .01 . The smallest $t$ value was for the 1-min delay and the largest for the 16-min delay.

The zero-delay group in the present experiment constitutes a replication of Experiment 1. The mean aftereffect for that group was $13.50 \%$, and the mean for Experiment 1 was $14.37 \%$; those means do not differ significantly $[\mathrm{t}(18)=.15]$. For comparison, the results of Experiment 1 are shown with the results of the present experiment in Figure 4. The standard error of the mean was slightly greater for the zerodelay group in comparison with Experiment 1, but the variance was slightly, but not significantly,

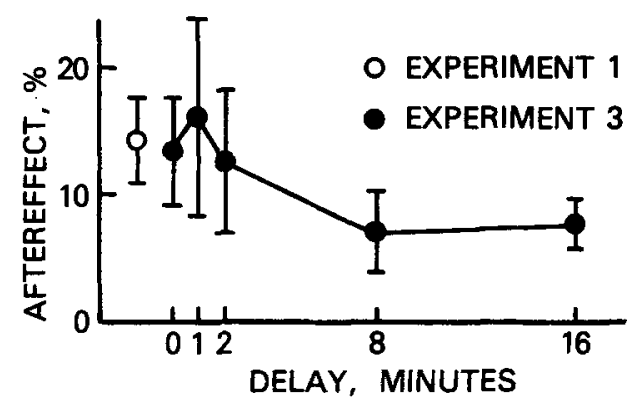

Figure 4. Aftereffect in relation to delay interval between inspection and test. Delay interval was zero for Experiment 1. Bars indicate \pm 1 standard error of the mean. 
smaller $[F(11,7)=1.10, p>.25]$. Thus, the results for the zero-delay group in the present experiment and the results of Experiment 1 compare very closely, in terms of both means and variances.

In the present experiment, as in Experiment 2, the means and variances are correlated. Thus, a $\log (X+10)$ transformation was carried out before doing an analysis of variance. There was no significant effect of delay interval $[\mathrm{F}(4,35)<1]$.

\section{Discussion}

While Figure 4 shows a decline in the magnitude of aftereffect with increasing length of delay, that decline was not statistically significant. The mean aftereffect was significantly greater than zero after the longest delay interval, and thus the present contingent aftereffect has a duration of at least 16 min. Bourne, Kepros, and Beier (1963) found that a simple kinesthetic figural aftereffect declined essentially to zero within a delay interval of $80 \mathrm{sec}$ between inspection and test. However, Wertheimer and Leventhal (1958) present data showing the retention and increase of residual kinesthetic figural aftereffects over successive inspection periods separated by $24 \mathrm{~h}$ and also report the retention of such aftereffects over a period of 32 weeks; but, as those workers note, their measurement procedures pose some methodological problems. The present contingent aftereffect appears to last considerably longer than the simple kinesthetic figural aftereffect which Bourne et al. measured, but the long-term durationif any-of the present aftereffect remains to be assessed.

\section{GENERAL DISCUSSION}

Two fundamentally different kinds of explanations have been proposed to account for contingent aftereffects in the visual modality, models based on (1) neural adaptation (fatigue), and (2) classical conditioning. After a brief description of those models, their possible application to the present tactual-kinesthetic aftereffect will be discussed.

To produce the McCollough effect, the subject alternately views a horizontal grating of red and black lines and a vertical grating of green and black during an inspection period of several minutes. Horizontal and vertical achromatic test gratings then appear, respectively, greenish and pinkish. Thus, the McCollough effect is an orientation-contingent complementary color aftereffect. McCollough suggested that color-coded orientation-specific edge detectors might account for the observed contingent aftereffect-and, indeed, a few such detectors were later found in the visual cortex of the monkey (Hubel \& Wiesel, 1968). Nevertheless, McCollough's explanation has been criticized on several grounds
(Harris \& Gibson, 1968; Murch, 1972, 1976; Skowbo, Timney, Gentry, \& Morant, 1975).

McCollough's explanation is essentially a neural adaptation, or fatigue, model. Adapting a colorcoded orientation detector to a particular color decreases its sensitivity to that color; a properly oriented achromatic test grating then produces a complementary color aftereffect. The most telling criticisms of that neural fatigue model are based on the extremely long duration of the McCollough effect-nearly 3 months under some conditions (Jones \& Holding, 1975). Several workers (for example, Mayhew \& Anstis, 1972; Murch, 1976) have argued that the McCollough effect has more of the characteristics of a conditioning phenomenon than of a process of neural fatigue.

In a classical conditioning model of the McCollough effect (Murch, 1976), the orientation of a grating is a conditioned stimulus, the inspection color paired with that orientation is an unconditioned stimulus, and the aftereffect color is a conditioned response. (Since there are two orientations and two colors, there are two conditioning processes going on during the inspection period.) But a problem arises: After pairing the horizontal orientation with the color red, for example, when that orientation is then presented in the absence of the red unconditioned stimulusthat is, in an achromatic test grating-the horizontal orientation elicits the complement of the color with which it was previously paired. It is as though pairing a bell and meat powder were to produce a drying of a dog's mouth as a conditioned response to the bell alone-a result not typically observed in Pavlovian conditioning. Thus, the traditional model of classical conditioning does not account for the McCollough effect entirely satisfactorily, as Skowbo et al. (1975) have also suggested. Modifications of the traditional classical conditioning model may fit the McCollough effect somewhat better, but at the expense of assumptions that represent great departures from the fundamental principles of classical conditioning (Leppmann, 1973; Murch, 1976; Skowbo, Gentry, Timney, \& Morant, 1974). The McCollough effect and other contingent aftereffects certainly display many of the characteristics of conditioning processes, but those aftereffects also display features that cannot be accommodated within a traditional model of classical conditioning.

The long duration of the present contingent aftereffect, in comparison with the simple kinesthetic figural aftereffect of Bourne et al. (1963), suggests the possibility that conditioning may play some role in the present phenomenon. Applying the classical conditioning model to the present aftereffect, orientation is a conditioned stimulus and size of finger span is an unconditioned stimulus. Pairing the horizontal orientation, for example, with a wide 
finger span should make the horizontal dimension of the test square feel wide-but that dimension feels narrow instead. Thus, the same objection to the traditional model of classical conditioning as an explanation of the McCollough effect applies to that model as an explanation of the present aftereffect.

The results of Experiment 2 may pose another possible difficulty for the classical conditioning model. If the magnitude of the aftereffect is taken as a measure of the strength of conditioning, and if the difference between the length of the horizontal and vertical dimensions of each inspection block is taken as a measure of the strength of the unconditioned stimulus, then Figure 3 shows that the strongest conditioning was produced by an unconditioned stimulus of intermediate strength-namely, the H70-V30 inspection block. Under the conditioning model, a strong unconditioned stimulus should be expected to produce a stronger conditioned response, but the H90-V10 inspection block produced a numerically-though not significantly-weaker aftereffect than the H70-V30 block. On the other hand, as noted earlier, the relationship between the magnitude of the contingent aftereffect and the dimensions of the inspection blocks is consistent with the results of studies of simple kinesthetic figural aftereffects (Charles \& Duncan, 1959; Köhler \& Dinnerstein, 1947). Thus, the present aftereffect may display more of the characteristics of sensory processes and fewer characteristics of conditioning.

An extension of McCollough's neural adaptation model may be applicable to the present contingent aftereffect. Suppose that some of the "size detectors" responsible for simple kinesthetic figural aftereffects (Köhler \& Dinnerstein, 1947) are also coded in terms of hand and finger orientation. In that case, the present contingent aftereffect might result from adapting a set of such size detectors to a narrow finger span in one orientation and a wide span in some other orientation. In a formal sense, the present possible explanation closely parallels McCollough's neural adaptation model. A similar possible explanation was advanced by Walker and Shea (1974) to account for the location-contingent size aftereffects described earlier. The present explanation is highly speculative since there is no neurophysiological evidence of any orientation-coded tactual-kinesthetic size detectors.

There are strong analogies between all of the contingent aftereffects demonstrated so far, regardless of the sensory modalities involved, whether visual or tactual-kinesthetic. Thus, contingent aftereffects occuring in different modalities may share some common sensory or conditioning processeswhatever those processes may be.

\section{REFERENCES}

Bourne, L. E., JR., Kepros, P. G., \& Beier, E. G. Effect of postinspection delay upon kinesthetic figural aftereffects. Journal of General Psychology, 1963, 68, 37-42.

Charles, J. P., \& Duncan, C. P. The distance gradient in kinesthetic figural aftereffect. Journal of Experimental Psychology, 1959, 57, 164-170.

Favreau, O. E., Emerson, V. F., \& Corballis, M. C. Motion perception: A color-contingent aftereffect. Science, 1972, 176 , 78-79.

Grbson, J. J. Adaptation, after-effect and contrast in the perception of curved lines. Joumal of Experimental Psychology, 1933, 16, 1-31.

Harris, C. S., \& Gibson, A. R. Is orientation-specific color adaptation in human vision due to edge detectors, afterimages, or "dipoles"? Science, 1968, 162, 1506-1507.

Held, R., \& Shattuck, S. Color- and edge-sensitive channels in the human visual system: Tuning for orientation. Science, $1971,174,314-316$.

HePler, N. Color: A motion-contingent aftereffect. Science, $1968,162,376-377$.

Hubel, D. H., \& Wiesel, T. N. Receptive fields and functional architecture of monkey striate cortex. Joumal of Physiology, $1968,195,215-243$.

Jones, P. D., \& Holding, D. H. Extremely long-term persistence of the McCollough effect. Joumal of Experimental Psychology: Human Perception and Performance, 1975, 1, 323-327.

KOHLER, I. The formation and transformation of the perceptual world. Psychological Issues, 1964, 3, 1-173.

KöhleR, W., \& Dinnerstein, D. Figural aftereffects in kinesthesis. In Miscellanea psychologica: Albert Michotte. Louvain, Belgium: University of Louvain, 1947.

KöhleR. W., \& W WLLACH, H. Figural after-effects: An investigation of visual processes. Proceedings of the American Philosophical Society, 1944, 88, 269-357.

LEPPMANN, P. K. Spatial frequency dependent chromatic aftereffects. Nature, 1973, 242, 411-412.

MaYhew, J. E. W., \& Anstis, S. M. Movement aftereffects contingent on color, intensity and pattern. Perception \& Psychophysics, 1972, 12, 77-85.

McCollovgr, C. Color adaptation of edge-detectors in the human visual system. Science, 1965, 149, 1115-1116.

Murch, G. M. Binocular relationships in a size and color orientation specific aftereffect. Journal of Experimental Psychology, 1972, 93, 30-34.

MUrCh, G. M. Classical conditioning of the McCollough effect: Temporal parameters. Vision Research, 1976, 16, 615-619.

Skowbo, D., Gentry, T., Tmmey, B., \& Morant, R. B. The McCollough effect: Influence of several kinds of visual stimulation on decay rate. Perception \& Psychophysics, 1974, 16, 47-49.

Skowbo, D., Timney, B. N., Gentry, T. A., \& Morant, R. B. McCollough effects: Experimental findings and theoretical accounts. Psychological Bulletin, 1975, 82, 497-510.

StromeYer, C. F., III, \& MANSField, R. J. W. Colored aftereffects produced with moving edges. Perception \& Psychophysics, 1970, 7, 108-114.

WALKER, J. T. A texture-contingent visual motion aftereffect. Psychonomic Science, 1972, 28, 333-335.

WALKER, J. T., \& SHEA, K. S. A tactual size aftereffect contingent on hand position. Journal of Experimental Psychology, 1974, 103, 668-674.

WERTheIMER, M. Constant etrots in the measurement of figural aftereffects. American Journal of Psychology, 1954, 67, 543-546.

Wertheimer, M., \& LeVenthal, C. M. "Permanent" satiation phenomena with kinesthetic figural aftereffects. Joumal of Experimental Psychology, 1958, 55, 255-257. 


\section{NOTE}

1. It would be possible to use as a control measure each subject's preinspection judgment of the H50-V50 test block. However, in the preinspection measures there is a strong linear relationship between the subjects' judgments of the five preinspection blocks and the objective dimensions of the blocks (see Figure 2). Using the mean of all five preinspection judgments is equivalent to solving a linear regression equation for the subjective per- centage difference associated with an objective percentage difference of zero-that is, the objective percentage difference for the H50-V50 block. The mean of the five preinspection measures takes all of the preinspection judgments into account, and thus provides a less variable control measure than the judgment of a single block would provide.

(Received for publication August 5, 1977; revision accepted October $9,1977$. 